\title{
Measuring Factors That Influence Customers' Selection on Wealth Management Services in Taiwan
}

\author{
Hsin-Hue Chang, Min-Li Yao* \\ Department of Finance, Ming Chuan University, Taiwan \\ *Corresponding Author: mlyao@mail.mcu.edu.tw
}

Copyright $(2018$ by authors, all rights reserved. Authors agree that this article remains permanently open access under the terms of the Creative Commons Attribution License 4.0 International License

\begin{abstract}
The aim of this study is to investigate the key factors that influence customers' selection of wealth management (WM) services in Taiwan. We used a face-to-face interview to execute a two-stage questionnaire survey and employed an exploratory factor analysis (EFA) and a confirmatory factor analysis (CFA) to measure factors influencing customers' selection of WM services. The results of EFA suggest that factors consisting of brand image, perceived value, and financial consultants' service quality, might influence customers' selection of WM services. CFA results further provide evidence that those factors significantly account for customers' overall satisfaction. The moderating analysis result however reveals that married and single groups have different views on selecting a WM services. The single customers are more likely to rely on brand images in the choice of WM services, whereas the married customers are more likely to place the emphasis on consultants' service quality. This study provides a chance for WM service providers to understand the key factors that impact customer's selection decision, so providers can address those key factors in their marketing strategy. Therefore, they can compete in this intensive market in better shape. In sum, consultants' service quality is the basic requirement for customers while perceived value plays the important role for financial institutions to excel in the WM markets.
\end{abstract}

Keywords Brand Image, Confirmatory Factor Analysis, Consultants' Service Quality, Perceived Value, Taiwan, Wealth Management

\section{Introduction}

Since the Financial Supervisory Commission (FSC) in Taiwan published compliance guidelines for financial institutions (FIs) offering wealth management (WM) services in 2005, the FIs have aggressively developed their private WM services and succeeded in creating significant commission income. According to Global Views Monthly (February, 2013), at the end of 2011, with the minimum investment requirements of NT\$3 million, the book balance of WM products had amounted to NT\$2.23 trillion for High-Net-Worth Individuals (HNWIs). While affluent individuals will account for approximately $27.6 \%$ of the adult population in a few years, the WM market will become attractive not only in terms of size but also in terms of value.

The financial crisis in 2008 greatly impacted not only the wealth but also the investing philosophies of many customers. Customers who rely on WM services claimed that the FIs did not do their best to manage their wealth and the FIs' consultants did not explicitly inform the overall level of financial risks. Some customers even made legal claims against their FIs. As a result, many customers lost confidence in FIs and became more risk averse. From the point of view of FIs, the ways through which they might retrieve the trust of customers become extremely important for regaining their dominance in the WM market. Understanding what the customers want and need is critical for success because those might play important roles during the process of selecting WM services. As such, our purpose is to investigate the key factors that influence customers' selection on WM services (i.e., a WM provider).

Chan and Chan [10] adopt the theory of planned behavior (TPB) to identify the factors and attitudinal preferences that influence the selection on WM services by Taiwanese customers who reside in China. Results find that feeling of trustworthiness, provision of flexible services, and feeling of cultural affinity are the most crucial factors that impact Taiwanese customers' selection decision on WM services. They conclude that 'guan-xi' (relationship) plays an important role during the marketing process of WM services. In addition, by using an analytic hierarchy process (AHP) approach, Yu and Ting [43] adopt image, products, and service quality to investigate whether the factors influence Taiwanese customers' selection on WM services. They find that the customers' concern about WM services prioritizes by service quality, products and then image.

Many FIs received legal claims during the financial crisis in 2008 because of the violation of professional ethics, which tarnished their good reputation. Reputation is 
closely associated with brand image (Smith et al. [35]; Yu and Ting [43]; Ting [39]), which has been identified earlier as one of the customers' concerns. Therefore, following prior studies, we investigate the effect of brand image on customers' selection on WM services. Although product characteristics (e.g., risk, return, fee, etc.) might influence customers' selection on WM services, FIs are almost able to offer very similar products and services because financial products and services are easily duplicated. Therefore, following similar marketing studies (Al-Hawari et al. [2]; Soureli et al. [37]), we highlight perceived value rather than product characteristics in this study.

Financial consultants as FIs' representatives essentially perform WM functions and personally establish contact with customers. The consultants' performance and service quality are directly evaluated by their customers. Indeed, it is very common in Taiwan that when financial consultants move to another FI, customers follow them and switch their accounts over to that FI as well. This implies that consultants' service quality might be a key factor influencing WM development for FIs because good service quality results in a good rapport. Therefore, we specifically pick the financial consultants' service quality rather than the FIs' in this study. In summary, we focus mainly on dimensions consisting of brand image, perceived value, and consultants' service quality to examine how those factors influencing Taiwanese customers' selection on WM services.

We execute a two-stage questionnaire and employ exploratory factor analysis (EFA) and confirmatory factor analysis (CFA) to measure factors influencing customers' selection on WM services. The results of EFA extract three factors, which are named as brand image, perceived value, and consultants' service quality, respectively. The findings of second-order CFA further suggest that the three factors (first-order factors) account significantly for customers' overall satisfaction with WM services (second-order factor) (Chang et al. [11]; Li et al. [28]). Furthermore, the results of moderating analysis show that marital status moderates the selection on WM services, whereas gender does not.

Our research offers several substantial contributions. Firstly, unlike previous studies, we highlight the service quality of financial consultants rather than that of the FIs that consultants work for. The reason is that the relationship between financial consultants and WM customers is more direct and close, especially not only true in Taiwan's market but also in the whole East Asian markets. To understand the role of financial consultants in the East Asian WM market, it is therefore necessary to differentiate financial consultants' service quality from the FIs'. Secondly, we adopt an original and appropriate methodology to perform the empirical analysis. A two-stage questionnaire and two factor analyses (EFA and CFA) are employed to measure factors influencing customers' selection on WM services. To the best of our knowledge, few studies adopt both EFA and CFA to examine the WM issues. Thirdly, our empirical results can provide some strategic implications that might help customers select WM services on one hand and assist FIs in promoting their financial products and services on the other hand. Few studies have investigated the factors influencing customers' selection on WM services in Asian markets. Our study attempts to enrich the literature, and the results have implications for FIs developing marketing strategies in the territory of WM services.

The study is organized as follows: section 2 reviews the theoretical background and forms factor constructs for this study, section 3 describes the estimation and questionnaire procedures, section 4 illustrates the empirical results, and section 5 offers concluding remarks and strategic implications.

\section{Literature Review and Hypotheses Development}

Marketing studies employ different dimensions to investigate factors influencing customers' selection on banking services. Based on prior studies, we mainly investigate whether brand image, perceived value, and consultants' service quality influence customers' selection on WM services.

\subsection{Brand Image}

Brand image is very subjective from consumer to consumer; yet, it is a key criterion used to choose a company's products and services (Crosby et al. [14]; Soureli et al. [37]; Yu and Ting [43]; Ting [39]). Brand refers to clusters of associations in consumers' minds, adding value to consumers' experiences and hence driving their positive reactions toward the company (Keller [25]). Brand image influences consumers' purchasing behavior, especially when it is difficult to differentiate among products or services on the basis of tangible features (Mudambi et al. [30]). In addition, behavioral finance studies argue that brand image is a heuristic, which drives investors to make investment decision quickly (Barber and Odean [6]). Many studies find that individual customers prefer to invest in stocks with big (brand) name because well-known companies are often associated with good stock (Frieder and Subrahmanyam [18]; Ackert and Church [1]; Statman et al. [38]; Filbeck et al. [17]).

A positive brand image can strengthen consumers' confidence in a company, and further build loyalty (Smith et al. [35]). In addition, through word-of-mouth, FIs can further attract new customers and develop strong customer relationship (de Chernatony and Cottam [16]; O'Loughlin and Szmigin [31]; Kim and Ghantous [27]). Some studies indicate that in real business practices, when customers feel that financial products are associated with potentially high perceived risk, the role of a positive brand can act as a risk-reducing device in reassuring the consumers (de Chernatony and Dall'Olmo Riley [15]; de Chernatony and Cottam [16]; Kim and Ghantous [27]). Soureli et al. [37] 
find that firm image measured by good impression and high reputation influences customers' cross-buying intentions in the banking industry. $\mathrm{Yu}$ and Ting [43] indicate that firm image measured by professionalism, morality, and reliability affects consumers' selection on WM services. Therefore, our study assumes that brand image is an important factor that positively influences customers' selection on WM services. The hypothesis is shown as follows.

H1: Brand image positively influences customers' selection on WM services

\subsection{Perceived Value}

Zeithaml [44] indicates that perceived value could be defined as consumers' judgment about a product's overall excellence or superiority. The author further classifies value into four groups: (1) value is low price, (2) value is what I want in a product, (3) value is the quality I get for the price I pay, and (4) value is what I get for what I give. Consequently, perceived value consists of low price, utility, and the trade-off between give (price) and get (quality). Behavioral finance indicates that mental accounting may influence consumers' (investors') decisions. For example, Thaler [40] indicates that consumers frame their utility into different accounts, consisting of acquisition utility and transaction utility. Acquisition utility represents the pleasure from obtaining a product, while transaction utility derives from a comparison of actual prices with a reference point such as the regular price. Parasuraman and Grewal [32] argue that perceived value consists of four factors: acquisition value, transaction value, in-use value, and redemption value. Torkzadeh and Dhillion [41] point out those respondents generally refer to more bargain possibilities about the product value issue. They conclude that product value is a significant fundamental factor influencing consumers' online shopping decisions.

Khazeh and Decker [26] and Boyd et al. [8] indicate that service-charge policy is the most important factor impacting consumers' decision-making in the banking industry. Al-Hawari et al. [2] find that service charge, acceptable fees, and competitive fees can be used to account for customers' perceived price quality (i.e., perceived value). Soureli et al. [37] use a structural equation model (SEM) to examine the factors influencing customers' cross-buying in the financial industry. Results show that perceived value directly influences customer satisfaction and indirectly impacts the intention to cross-buy. Therefore, our study assumes that perceived value positively influences customers' selection on WM services. The hypothesis is shown as follows.

H2: Perceived value positively influences customers' selection on WM services

\subsection{Consultants' Service Quality}

Parasuraman et al. [33] [34] propose a disconfirmation model and adopt reliability, responsiveness, assurance, empathy, and tangibility to measure customers' perceived service quality. According to the disconfirmation model, service quality is the comparison between the expectations and the perceptions of the service. The score difference between expectations and perceptions is used to represent service quality. Because the disconfirmation model suffers from problems with regards to the measurement of expectations, some studies argue that measuring perceptions alone might be a better indicator of service quality (Andaleeb and Basu [3]; Mittal and Lassar [29]).

Service quality is an important factor that influences customers' intentions of purchasing bank services (Bloemer et al. [7]). Kaynak and Kucukemiroglu [24], and Boyd et al. [8] find that fast and efficient service and friendliness are the most important criteria when customers select a commercial bank. Jayawardhena [21] investigates the service quality of e-banking and finds that the access and web interactions are the most significant factors influencing customers' selection on e-banking services.

Chan and Chan [10] find that Taiwanese customers who reside in China prefer to choose FIs from their home country due to the provision of flexible services. $\mathrm{Yu}$ and Ting [43] use attitude, communication, confidentiality, and convenience to measure service quality in Taiwan's WM industry. Results show that communication and convenience are the two most important critical points when customers choose WM services. Since customers are mainly and directly in contact with their financial consultants, it is necessary to highlight the financial consultants' service quality rather than the FI's. Our study, thus, adopts consultants' service quality (CSQ) as a criterion to examine whether CSQ positively influences customers' selection on WM services. The hypothesis is shown as follows.

H3: Consultants' service quality positively influences customers' selection on WM services

\section{Methodology}

\subsection{The Conceptual Framework}

Based on prior research, we focus on brand image (BI), perceived value $(\mathrm{PV})$, and consultants' service quality (CSQ) and adopt the second-order CFA to identify whether those factors influence customers' selection on WM services. The conceptual model is shown in Figure 1. The proposed model consists of three first-order factors: BI, PV, and CSQ and one second-order factor: SAT, which indicates that the three first-order factors can account for the second-order factor. As suggested by Chang et al. [11], the second-order factor can represent customers' overall satisfaction with WM services. Thus, we name it as satisfaction (SAT). In addition, we use gender and marital status as moderating variables to examine whether gender and marital status moderate the relationship between the second-order factor and the first-order factors. 


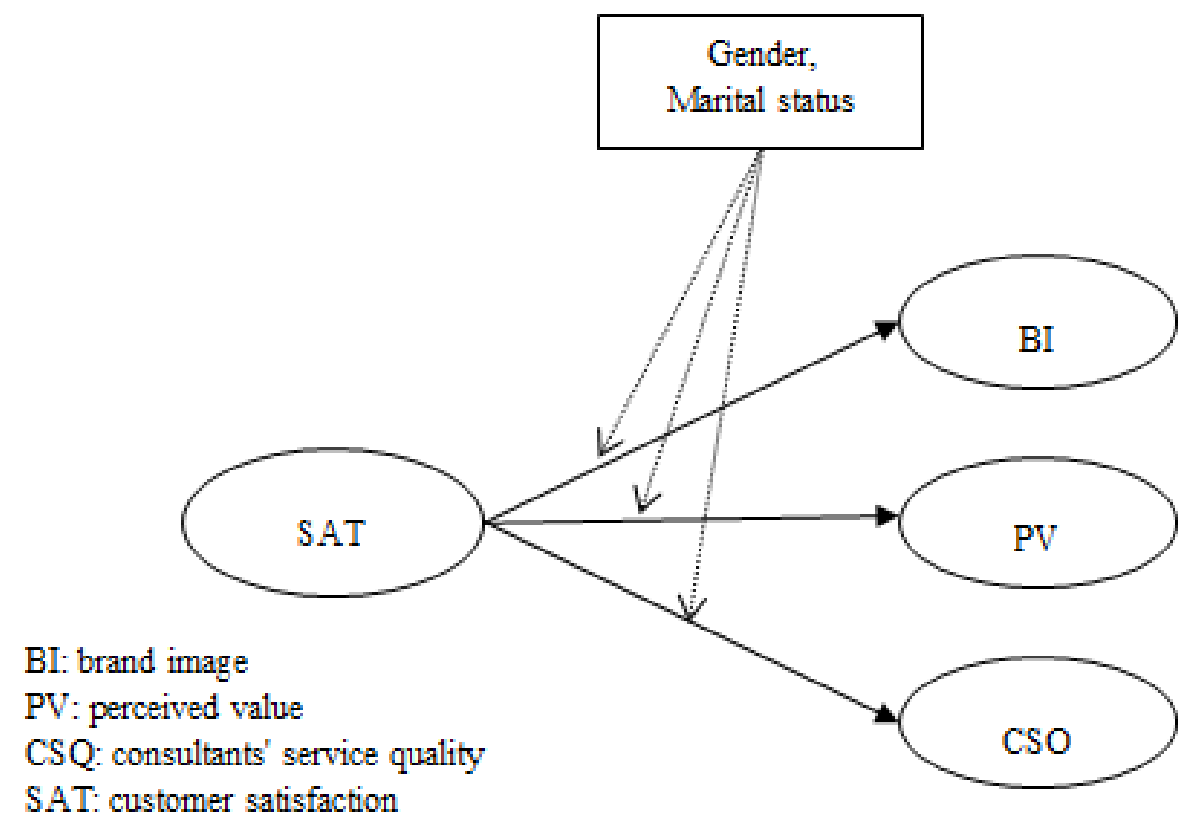

Figure 1. The conceptual model

\subsection{Questionnaire}

Based on relevant marketing research in banking and WM services (Soureli et al. [37]; Yu and Ting [43]; Chan and Chen [10]; Ting [39]), we use 13 items to measure three dimensions consisting of brand image (4 items), perceived value (4 items), and consultants' service quality (5 items), as shown in Table 1. A 7-point Likert-type scale is used, with a range from 1 (strongly disagree) to 7 (strongly agree). Seven financial consultants participate in the questionnaire pretesting. The results do not show any obvious problems in the questionnaire design, which implies that the items have face validity.

Table 1. Measurement items

\begin{tabular}{cc}
\hline Dimension & Question item \\
\hline BI (brand image) & impression \\
BI1 & reputation \\
BI2 & professionalism \\
BI3 & morality \\
BI4 & \\
PV (perceived value) & customer differentiation \\
PV1 & acceptable fees \\
PV2 & competitive fees \\
PV3 & competitive terms \\
PV4 & \\
CSQ (consultant's services & \\
quality) & appropriate recommendation \\
CSQ2 & abundant experience \\
CSQ3 & speedy response \\
CSQ4 & friendliness \\
CSQ5 & offers and benefits \\
\hline
\end{tabular}

We adopt non-random sampling and use a face-to-face interview to execute the questionnaire survey. The questionnaire was distributed over the period of January 2012 to March 2012. We perform a two-stage questionnaire. In the first stage, three dimensions consisting of 13 items are used in the questionnaire posed to Executive Master of Business Administration (EMBA) students. The obtained quantitative data is employed to measure factors influencing customers' selection on WM services by EFA. During the second stage, the items based on the results of EFA are deployed in the questionnaire again through three WM providers. Afterward, these responses obtained from the second-stage questionnaire are used to identify the conceptual model by CFA.

\subsection{Factor Analysis}

Second-order CFA relies on prior theoretical or empirical work, which provides plausible alternative models that can be validated by using new data (Chang et al. [11]). Thus, we perform two factor analyses. The factors obtained by the EFA are validated through the CFA. When conducting the EFA, we eliminate items as long as their communalities are less than 0.6 , and use the principal components method for extraction and the varimax method for rotation. We also employ Cronbach's $\alpha$ to examine the reliability of each factor construct. Furthermore, the second-order CFA is employed to identify the conceptual model proposed again. After performing the common method variance test, we use the indices consisting of goodness of fit, validity, and reliability to examine whether the estimated model is valid. 


\section{Empirical Results}

\subsection{Sample Summary}

Table 2. Demographic statistics

\begin{tabular}{ccc}
\hline Demographic variable & Classification & N $(\%)$ \\
\hline Gender & Male & 43.09 \\
Farital status & Married & 56.91 \\
& Single & 62.06 \\
Income & & 37.94 \\
& $<$ NT\$ 1 million & 29.88 \\
& NT\$ 1-1.5 million & 47.65 \\
& NT\$ 1.5-3 million & 16.30 \\
& NT\$ 3-5 million & 5.93 \\
& $>$ NT\$ 5 million & 0.25 \\
& & \\
Investment amount & <NT\$ 0.5 million & 15.06 \\
& NT\$ 0.5-1 million & 24.20 \\
& NT\$ 1-3 million & 33.33 \\
& NT\$ 3-5 million & 20.25 \\
& NT\$ 5-10 million & 7.16 \\
& NT\$ 10 million & 0.25 \\
\hline
\end{tabular}

Note: 1 US\$ is about 30 NT\$.

In the first-stage questionnaire, among the 215 EMBA student respondents, we yield 196 responses. Among these, $78 \%$ have investment experience. During the second-stage questionnaire, we collect 453 from 530 samples through three WM providers; among these, 427 responses are valid. Table 2 shows the results of the second-stage questionnaire. Of the 427 respondents, $43.09 \%$ and $56.91 \%$ are male and female, respectively. The marital status proportions with married and single are $62.06 \%$ and $37.94 \%$, respectively. The annual income with NT\$1-1.5 million accounts for $47.65 \%$, which implies that a larger ratio of the sample is above the per capita income (NT\$0.62 million). The investment amount of NT $\$ 1-3$ million is about $33.33 \%$.

We classify respondents into two groups, i.e., early or late groups and compare the respondents between these two groups. The result shows that there are no significant differences between the majority of the responses from the early and late groups (F statistic $=0.058$, p-value $=0.809$ ) (Connors and Elliot [13]; Tu et al. [42]). Thus, the non-response bias problem could be mitigated in this study.

\subsection{Results of Exploratory Factor Analysis}

We use 196 responses and 13 items to identify a concise set of factor constructs. After a few extractions, the value of Bartlett's test of sphericity is 970.192 with significance at the $1 \%$ level; this value is used to assess the overall significance of the correlation matrix. In addition, the value of the Kaiser-Meyer-Olkin (KMO) is 0.84 , which indicates that the variables meet the fundamental requirements for factor analysis (Hair et al. [19]). Therefore, the sample is appropriate for the analysis.

As shown in Table 3, a 3-factor 9-item measurement model is obtained in terms of CSQ, PV, and BI. It accounts for $71.97 \%$ of the variance; the explained variances for CSQ, PV, and BI are $27.84 \%, 22.66 \%$, and $21.47 \%$, respectively. We further use Cronbach's alpha value to measure the reliability of each factor. The values for CSQ, $\mathrm{PV}$, and $\mathrm{BI}$ are $0.82,0.82$, and 0.83 , respectively, which implies that each factor satisfies the test of reliability.

As a result, WM customers require consultants' speedy response, offers and benefits, abundant experience, and appropriate recommendation. In addition, they prefer to obtain competitive fees, competitive terms, and customer differentiation. Moreover, they rely on FIs' reputation and professionalism in their selection on WM services. The explained variance values for the three factors are quite close to each other, with a range from 21.47 to 27.84 . This implies that they might contain a certain concept when visualizing together (Chang et al. [11]). Therefore, the second-order CFA should be appropriate in this study.

Table 3. Results of exploratory factor analysis

\begin{tabular}{|c|c|c|c|c|}
\hline Factor & Question item & Variance explained (\%) & Factor loading & Cronbach's alpha \\
\hline \multirow[t]{4}{*}{ CSQ } & CSQ3: speedy response & 27.84 & 0.795 & 0.82 \\
\hline & CSQ5: offers and benefits & & 0.789 & \\
\hline & CSQ2: abundant experience & & 0.747 & \\
\hline & CSQ1: appropriate recommendation & & 0.704 & \\
\hline \multirow[t]{3}{*}{ PV } & PV3: competitive fees & 22.66 & 0.860 & 0.82 \\
\hline & PV4: competitive terms & & 0.801 & \\
\hline & PV1: customer differentiation & & 0.743 & \\
\hline \multirow[t]{2}{*}{ BI } & BI2: reputation & 21.47 & 0.884 & 0.83 \\
\hline & BI3: professionalism & & 0.827 & \\
\hline
\end{tabular}

Note: Numbers are the magnitude of the factor loadings multiplied by 100. BI: brand image. PV: perceived value. CSQ: consultants' service quality. 


\subsection{Results of Confirmatory Factor Analysis}

Based on the results of EFA mentioned above, we redistributed the questionnaire with only 9 items left to validate whether the three factors influence customers' selection on WM services. We perform the second-order three-factor, first-order three-factor, and one factor CFA, respectively. Table 4 shows that the second-order CFA $\left(\chi^{2}=68.9, R M S E A=0.066\right)$ should be accepted as a "truer or better" representation of the model structure because of better goodness of fit (Chang et al. [11]).

We conduct Harman's one factor test to examine whether most of the question items jointly explain one general factor by EFA. The findings show that a single factor accounts for a majority of the variance $(45.40 \%)$, which is less than the common value of $50 \%$ (Podsakoff et al. [36]; Tu et al. [42]; Chen et al. [12]). Moreover, as shown in Table 4, the significant difference between the second-order three-factor CFA and the one-factor CFA $\left(\Delta \chi^{2}=929.32, \Delta \mathrm{df}=3, \mathrm{p}\right.$-value $\left.=0.000\right)$ shows that the common method variance is not a significant issue in this study (Podsakoff et al. [36]; Chen et al. [12]).

Table 4. Fit indices of proposed model and alternative models

\begin{tabular}{cccccc}
\hline Models & $\chi^{2}$ & $\mathrm{df}$ & $\Delta \chi^{2}$ & $\Delta \mathrm{df}$ & RMAEA \\
\hline $\begin{array}{c}\text { Second-order } \\
\text { three- factors } \\
\quad \text { CFA }\end{array}$ & 68.9 & 24 & & & 0.066 \\
$\begin{array}{c}\text { First-order } \\
\text { three- factors } \\
\text { CFA }\end{array}$ & 142.03 & 24 & 55.13 & 0 & 0.107 \\
$\begin{array}{c}\text { One-factor } \\
\text { CFA }\end{array}$ & 998.22 & 27 & 929.32 & 3 & 0.291 \\
\hline
\end{tabular}

Since $\chi^{2}$ is highly sensitive to sample size, the chi-square statistic must be interpreted with caution in most applications (Joreskog and Sorborn [23]). Table 5 show that the value of the chi-squared statistic divided by the degree of freedom is 2.87 , which is less than the threshold value of 3 . The value of RMSEA is 0.066 , which is less than the threshold value of 0.085 . Furthermore, in reference to the other fit statistics, all indices (GFI $=0.93$,
$\mathrm{AGFI}=0.87, \mathrm{NFI}=0.98, \mathrm{NNFI}=0.97, \mathrm{CFI}=0.99, \mathrm{RFI}=$ $0.97, \mathrm{IFI}=0.99, \mathrm{PGFI}=0.50, \mathrm{PNFI}=0.65, \mathrm{CN}=266.75$ ) are above a common threshold value except AGFI. As a result, the proposed model is valid.

Table 5. Goodness of Fit Indices for Second-Order CFA

\begin{tabular}{cccc}
\hline Model-data fit & Index & Statistic & Threshold \\
\hline \multirow{2}{*}{$\begin{array}{c}\text { Absolute fit } \\
\text { indices }\end{array}$} & $\chi^{2} / d . f$. & $68.90 / 24=2.87$ & $<3$ \\
& RMSEA & 0.066 & $<0.85$ \\
& GFI & 0.93 & $>0.9$ \\
& AGFI & 0.87 & $>0.9$ \\
& NFI & 0.98 & $>0.9$ \\
Incremental fit & NNFI & 0.97 & $>0.9$ \\
indices & CFI & 0.99 & $>0.9$ \\
& RFI & 0.97 & $>0.9$ \\
& IFI & 0.99 & $>0.9$ \\
Parsimonious fit & PGFI & 0.50 & $>0.5$ \\
indices & PNFI & 0.65 & $>0.5$ \\
& CN & 266.75 & $>200$ \\
\hline
\end{tabular}

Convergent validity is assessed by reviewing the t-test for the factor loadings, which are used to assess whether the observed variables are sufficient in representing their respective factor constructs. Table 6 shows that each factor loading of the construct factors has highly significant t-statistics, which implies that the proposed model meets the convergent validity (Anderson and Gerbing [4]). Average variance extracted (AVE) evaluates the amount of variance captured by the construct, and composite reliability (CR) reflects the internal consistency of the indicators measuring each construct (Bagozzi and Yi [5]). The study results show that all AVE and CR values are over the recommended value of 0.5 and 0.7 , respectively, which implies that the construct reliability is reached. Moreover, the root square value of the AVE for each construct is greater than the squared correlations between the constructs, which indicates that the distinct validity is satisfied (Hair et al. [19]; Hansen [20]).

Table 6. Results of validity and reliability

\begin{tabular}{|c|c|c|c|c|c|c|}
\hline Factor and question item & Factor loading & AVE & $\mathrm{CR}$ & $\mathrm{BI}$ & $\mathrm{PV}$ & CSQ \\
\hline BI & & 0.74 & 0.85 & $0.86^{2}$ & 0.65 & 0.44 \\
\hline $\mathrm{BI} 2$ : reputation & $0.97^{1}$ & & & & & \\
\hline BI3: professionalism & $0.73 * * *(12.33)$ & & & & & \\
\hline PV & & 0.72 & 0.88 & & 0.85 & 0.51 \\
\hline PV1: customer differentiation & 0.90 & & & & & \\
\hline PV3: competitive fees & $0.93 * * *(26.05)$ & & & & & \\
\hline PV4: other competitive terms & $0.69 * * *(16.48)$ & & & & & \\
\hline CSQ & & 0.61 & 0.86 & & & 0.78 \\
\hline CSQ1: appropriate recommendation & 0.75 & & & & & \\
\hline CSQ2: abundant experience & $0.82 * * *(16.87)$ & & & & & \\
\hline CSQ3: speedy response & $0.75^{* * *}(14.80)$ & & & & & \\
\hline CSQ5: offers and benefits & $0.79 * * *(15.56)$ & & & & & \\
\hline
\end{tabular}

BI: brand image; PV: perceived value; CSQ: consultants' service quality; AVE: average variance extracted; CR: composite reliability. 1: Since the first observed variable of each factor is used to standardize the other factor loadings in the same factor, its t-value does not exist. T-values are shown in parentheses. $* * *$ : significance at $1 \%$ level. 2 : The diagonal values represent the root square of the average variance extracted (AVE) for each construct. Non-diagonal values are the squared correlations between the constructs. 


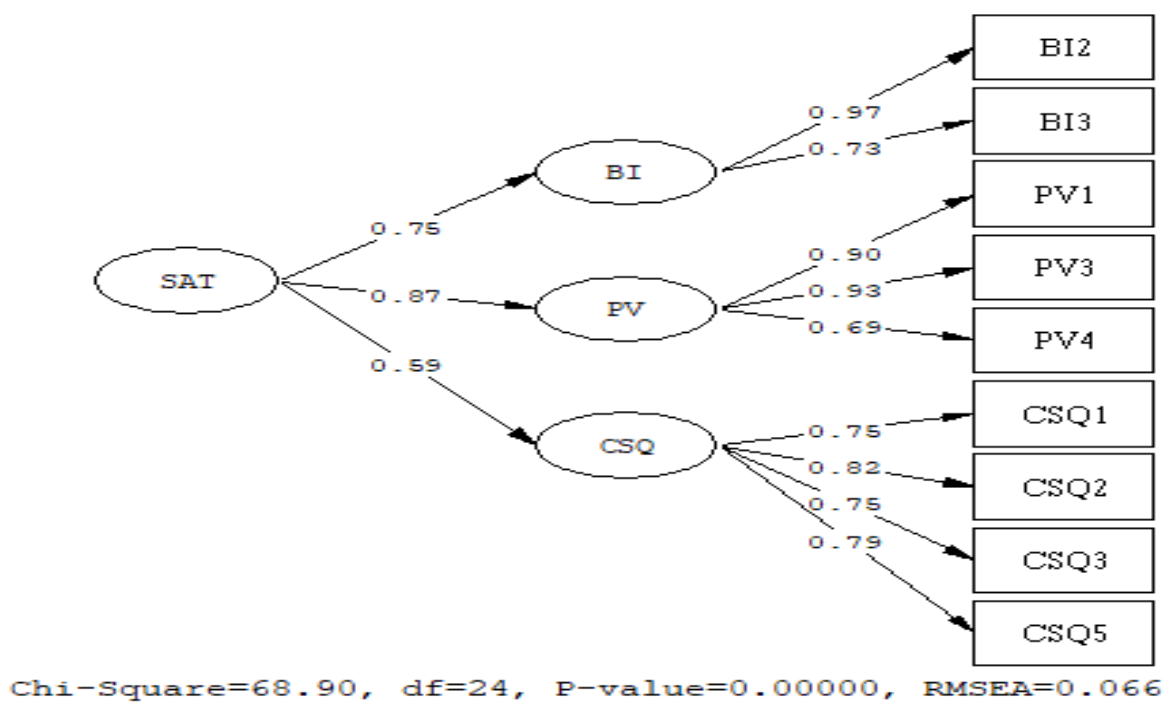

Figure 2. First-order CFA results

Table 7. Results of path relationship

\begin{tabular}{ccccc}
\hline Path relationship & coefficient & t-value & R-square & Hypothesis \\
\hline $\mathrm{SAT} \rightarrow \mathrm{BI}$ & $0.75^{* * *}$ & 14.62 & 0.57 & Acceptance \\
$\mathrm{SAT} \rightarrow \mathrm{PV}$ & $0.87^{* * *}$ & 15.09 & 0.75 & Acceptance \\
$\mathrm{SAT} \rightarrow \mathrm{CSQ}$ & $0.59^{* * *}$ & 8.78 & 0.34 & Acceptance \\
\hline
\end{tabular}

${ }^{* * *}$ : significance at $1 \%$ level. BI: brand image; PV: perceived value; CSQ: consultants' service quality; SAT: customer satisfaction.

Path coefficients, which are the standardized total effects of exogenous latent variables (i.e., the second-order factor: SAT) on endogenous latent variables (i.e., the first-order factors: BI, PV, and CSQ) are used to assess whether the proposed path relationships are substantiated. Figure 2 shows the results of the proposed model, and Table 7 shows that all path coefficients $(0.75,0.87$, and 0.59$)$ are significant, which indicates that three hypotheses are as suggested. The first-order factors can account for the second-order factor due to the significant and high path coefficients. As a result, brand image, perceived value, and consultants' service quality are key dimensions in customers' selection on WM services, and the second-order factor can be used to represent customers' overall satisfaction with WM services.

The study results find that customers rely on FIs' reputation and professionalism to select WM services due to the specific function of the brand as a risk-reducing device through the trust it conveys (de Chernatony and Dall'Olmo Riley [15]). During the 2008 financial crisis, customers accused their FIs of unclear explanations and demonstrations about the investment risks associated with structured products, which resulted in their huge losses. To retrieve and maintain brand image, FIs should minimize negative opinions from customers by improving employees' professionalism. In addition, customers prefer to obtain competitive fees, competitive terms, and customer differentiation (added value services), which implies that price strategies are important for FIs in attracting customers. HNWIs are more likely to obtain better upscale (differentiated) services. Moreover, customers require a speedy response, offers and benefits, abundant experience, and appropriate recommendations from the consultants, as identified by the CFA approach once again. The path coefficient of CSQ is less than those of $\mathrm{BI}$ and $\mathrm{PV}$, which may imply that the financial crisis in 2008 weakened the 'guan-xi' between financial consultants and customers.

In summary, the results of the EFA and CFA suggest the hypotheses that BI, PV, and CSQ influence customers' selection on WM services, respectively. The results of the EFA reveal that CSQ might be the most important factor that influences customers' selection on WM services, whereas the findings of the second-order CFA show that $\mathrm{PV}$ is the most significant factor influencing customers' overall satisfaction with WM services. As such, CSQ is the basic requirement for customers' selection on WM services, whereas PV is the best way for providers to excel in the WM market.

\subsection{Results of the Moderating Effect}

For the execution of the moderating analysis, the proposed model is carried out for each subgroup. Table 8 shows that all values of RMSEA and $\chi^{2} / d f$ are less than the threshold value of 0.85 and 3 , respectively, which implies that the data-model fit is appropriate for each subgroup. 
Table 8. Results of moderating effect

\begin{tabular}{|c|c|c|c|c|}
\hline & Male (N=184) & Female $(\mathrm{N}=243)$ & Married $(\mathrm{N}=265)$ & Single $(\mathrm{N}=162)$ \\
\hline RMSEA & 0.058 & 0.080 & 0.076 & 0.062 \\
\hline$\chi^{2} / \mathrm{df}$ & $38.78 / 24=1.62$ & $61.40 / 24=2.56$ & $67.12 / 24=2.80$ & $60.57 / 24=2.52$ \\
\hline $\mathrm{SAT} \rightarrow \mathrm{BI}$ & $0.73 * * *(11.5)$ & $0.77 * * *(9.16)$ & $0.71 * * *(11.72)$ & $0.95 * * *(9.56)$ \\
\hline $\mathrm{SAT} \rightarrow \mathrm{PV}$ & $0.87 * * *(12.25)$ & $0.86^{* *}(9.26)$ & $0.87 * *(12.64)$ & $0.84 * * *(7.92)$ \\
\hline $\mathrm{SAT} \rightarrow \mathrm{CSQ}$ & $0.61 * * *(7.10)$ & $0.55 * * *(5.44)$ & $0.61 * * *(7.51)$ & $0.49 * * *(4.00)$ \\
\hline$\Delta \chi^{2}(\Delta \mathrm{df})$ & $1.76(2)$ & & & $8.66(2)$ \\
\hline
\end{tabular}

BI: brand image; PV: perceived value; CSQ: consultants' service quality; SAT: customer satisfaction. T-values are shown in parentheses. *, **, ***: significance at the $10 \%, 5 \%$ and $1 \%$ level, respectively.

The path coefficients of the male (single) group are set to be equal to those of the female (married) group, and the estimation procedure is carried out again. A new $\chi^{2}$ statistics of the male (single) group is obtained and compared with the original $\chi^{2}$ of the male (single) group. If the $\Delta \chi^{2}$ is significant, then the moderating effect would exist (Johnson, [22]). The $\Delta \chi^{2}(\Delta d f=2)$ is 1.76 for the male sample and 8.66 for the single sample, respectively. This implies that marital status moderates the relationships between first-order factors and second-order factor, whereas gender does not. Since the path relationship between SAT and BI is greater in the single group, which indicates that single customers are more likely to rely on brand image for selecting WM services. The path relationship between SAT and CSQ is greater in the married group, which implies that married customers are more likely to place emphasis on consultants' service quality.

\section{Concluding Remarks and Strategic Implications}

\subsection{Concluding Remarks}

We use a two-stage questionnaire survey and employ the EFA and CFA to measure factors influencing customers' selection on WM services. The results of the EFA and CFA suggest the hypotheses that brand image (BI), perceived value (PV), and consultants' service quality (CSQ) influence customers' selection on WM services. Therefore, we propose a second-order CFA model, in which the first-order factors: brand image, perceived value, and consultants' service quality can account for the second-order factor: customer satisfaction (SA). The second-order factor can represent customers' overall satisfaction with WM services.

The results of the EFA reveal that CSQ might be the most important factor that influences customers' selection on WM services, whereas the findings of the second-order CFA show that PV is the most significant factor influencing customers' overall satisfaction with WM services. As such, CSQ is the basic requirement for customers' selection on WM services, whereas PV is the best way for providers to excel in the WM market. The results of moderating analysis show that there exist differences between married group and single person. The single customers are more likely to rely on brand image for selecting a WM provider, whereas the married customers are more likely to place the emphasis on consultants' service quality.

\subsection{Strategic Implications}

FIs with higher perceived value and better service quality in its consultants would definitely be able to maintain a good relationship with customers. This in turn would help foster the attitudinal loyalty of customers and maintain good retention rates. Brand image is an important factor influencing customers, especially single person, when they choose WM services. However, from customers' perspective, the way of the selection process that relies on brand image may result in heuristics bias (Barber and Odean [6]). Customers should be cautious with the trap of big name because truly understanding the features and rules of products are more important.

On the other hand, FIs should minimize negative opinions from customers and improve employees' professionalism. In addition, since competitive prices and terms are the criteria that determine customers' perceived value, FIs should disclose service charges in a transparent way and offer competitive fees to increase customers' utility. Furthermore, customers require that financial consultants have an abundant experience and knowledge to recommend appropriate products to them. In order to achieve this objective, consultants should undertake periodic in-job training and continuous education.

Customers often claim that FIs do not truly demonstrate the risk levels of financial products. Therefore, regulatory authorities can contribute to solving this issue by creating an environment that fosters greater degrees of information symmetry. Furthermore, a set of rules should be created that would allow authorities to lawfully investigate any disputed transactions or activities, so that investors can be 
better protected. As the experience of the 2008 financial crisis resulted in customer concerns with financial frauds and unfairness, improving investment protection would be a value-added device.

\section{REFERENCES}

[1] Ackert, L. F., and B. K. Church. 2006. "Firm Image and Individual Investment Decisions." The Journal of Behavioral Finance 7(3): 155-167.

[2] Al-Hawari, M., Hartley, N., and T. Ward. 2005. "Measuring Banks Automated Service Quality: A Confirmatory Factor Analysis Approach." Marketing Bulletin 16(1): 1-19.

[3] Andaleeb, S. S., and A. K. Basu. 1994. "Technical Complexity and Consumer Knowledge as Moderators of Service Quality Evaluation in the Automobile Service Industry," Journal of Retailing 70(4): 367-381.

[4] Anderson, J., and W. Gerbing. 1988. "Structural Equation Modeling in Practice: A Review and Recommended Two Stage Approach." Psychological Bulletin 27(1): 5-24.

[5] Bagozzi, R. P., and Y. Yi. 1988. "On the Evaluation of Structural Equation Models." Academic of Marketing Science 16: 76-94.

[6] Barber, B., T. Odean. 2008. "All that Glitters: The Effect of Attention and News on the Buying Behavior of Individual and Institutional Investors Studies." The Review of Financial Studies 21: 1-34.

[7] Bloemer, J., K. B., de Ruyter, and P. Peeters. 1998. "Investigating Drivers of Bank Loyalty: The Complex Relationship between Image, Service Quality and Satisfaction." International Journal of Bank Marketing 16(7): 276-298.

[8] Boyd, W. L., M., Leonard, and C. White. 1994. "Customer Preferences for Financial Services: An Analysis." International Journal of Bank Marketing 12(1): 9-15.

[9] Cameran, M., P. Moizer, and A. Pettinicchio. 2010. "Customer Satisfaction, Corporate Image, and Service Quality in Professional Services." The Service Industries Journal 30(3): 421-435.

[10] Chan, C., and A. Chan. 2011. "Attitude toward Wealth Management Services: Implications for International Banks in China." International Journal of Bank Marketing 29(4): 272- 292.

[11] Chang, J. C-J., G. Torkzadeh, and G. Dhillon. 2004. "Re-examining the Measurement Models of Success for Internet Commerce." Information Management 41: 577-584.

[12] Chen, C. C., M. M. Lin, and C. M. Chen. 2012. "Exploring the Mechanisms of the Relationship between Website Characteristics and Organizational Attraction." The International Journal of Human Resource Management 23(4): 867-885.

[13] Connors, J. J., and J. Elliot. 1995. "The Influence of Agriscience and Natural Resources Curriculum on Students'
Science Achievement Scores." Journal of Agricultural Education 36(3): 57-63.

[14] Crosby, L. A., K. R. Evans, and D. Cowles. 1990. "Relationship Quality in Services Selling: An Interpersonal Influence Perspective." Journal of Marketing 54: 68-81.

[15] de Chernatony, L., and R. F. Dall'Olmo. 1999. “Experts' Views about Defining Services Brands and the Principles of Services Branding." Journal of Business Research 46: 181-192.

[16] de Chernatony, L., and S. Cottam. 2006. "Internal Brand Factors Driving Successful Financial Services Brands." European Journal of Marketing 40(5/6): 611 - 633.

[17] Filbeck, G., R. Gormanb, and X. Zhaoa. 2013. "Barron's Most Respected Companies." Accounting and Finance 53: 623-641.

[18] Frieder, L., and A. Subrahmanyam. 2005. "Brand Perceptions and Market for Common Stocks." Journal of Financial and Quantitative Analysis 40(1): 57-85.

[19] Hair, J. F., R. E. Anderson, R. L. Tatham, W. C. Black. 1998. Multivariate data analysis (5th ed.), Upper Saddle River, New Jersey, Prentice Hall.

[20] Hansen, T. 2012. "Understanding Trust in Financial Services: The Influence of Financial Healthiness, Knowledge, and Satisfaction." Journal of Service Research 15(3):280-295.

[21] Jayawardhena, C. 2004. "Measurement of Service Quality in Internet Banking: The Development of An Instrument." Journal of Marketing Management 20: 185-207.

[22] Johnson, J. K. (1999). Strategic integration in industrial distribution channels: Managing the inter-firm relationship as a strategic asset. Journal of the Academy of Marketing Science, 27(1), 4-18.

[23] Joreskog, K. G., and D. Sorbom. 1989. LISREL VII User's Guide. Scientific Software, Inc., Mooresville, IN.

[24] Kaynay, E., and O. Kucukemiroglu. 1992. "Bank and Product Selection: Hong Kong." International Journal of Bank Marketing 10(1): 3-16.

[25] Keller, K. L. 1993. "Conceptualizing, Measuring Customer-Based Brand.” Journal of Marketing 57(1): 1-23.

[26] Khazeh, K., and W. H. Decker. 1992. "How Customers Choose Banks.” Journal of Retail Banking 14(4): 41-44.

[27] Kim N. P. and N. Ghantous. 2013. "Managing Brand Associations to Drive Customers' Trust and Loyalty in Vietnamese Banking." International Journal of Bank Marketing 31(6): 456 - 480.

[28] Li, F., N., Zhou, R. Kashyap, and Z. Yang. 2008. "Brand Trust as a Second-Order Factor: An Alternative Measurement Model." International Journal of Market Research 50(6): 817-839.

[29] Mittal, B., and W. M. Lassar. 1996. "The Role of Personalization in Service Encounters." Journal of Retailing 72(1): 95-109.

[30] Mudambi, S., P. Doyle, and V. Wong 1997. "An Exploration of Branding in Industrial Markets." Industrial 
Marketing Management 26(5): 433-446.

[31] O'Loughlin, D., I. Szmigin. 2005. "Customer Perspectives on the Role and Importance of Branding in Irish Retail Financial Services." International Journal of Bank Marketing 23(1): 8 - 27.

[32] Parasuraman, A., and D. Grewal. 2000. "The Impact of Technology on the Quality-Value-Loyalty Chain: A Research Agenda." Journal of the Academy of Marketing Science 28(1): 168-174.

[33] Parasuraman, A., V. A.Zeithaml, and L. Berry. 1985. "A Conceptual Model of Service Quality and Its Implications for Future Research." Journal of Marketing 49: 41-50.

[34] Parasuraman, A., V. A. Zeithaml, and L. Berry. 1988. SERVQUAL: A Multiple-item Scale for Measuring Consumer Perceptions of Service Quality." Journal of Retailing 64(1): 12-40.

[35] Smith, K. T., M. Smith, and K. Wang. 2010. "Does Brand Management of Corporate Reputation Translate into Higher Market Value?" Journal of Strategic Marketing 18(3): 201-221.

[36] Podsakoff, P. M., MacKenzie, S. B., Lee, J.-Y., \& Podsakoff, N. P. (2003). Common method biases in behavioral research: A critical review of the literature and recommended remedies. Journal of Applied Psychology, 88, 879-903.

[37] Soureli, M., B. R. Lewis, and M. K. Karantinou. 2008.
"Factors that Affect Consumers' Cross-Buying Intention: A Model for Financial Services." Journal of Financial Services Marketing 13(1): 5-16.

[38] Statman, M., K. L. Fisher, and D. Anginer. 2008. "Affect in a Behavioral Asset Pricing Model." Financial Analysts Journal 64(2): 20-29.

[39] Ting, H. I. 2017. "Factors Affecting Wealth Management Services: From Investors' and Advisors' Perspectives." The Journal of Wealth Management 20(1): 17-29.

[40] Thaler, R. 1985. "Mental Accounting and Consumer Choice." Marketing Science 4: 199-244.

[41] Torkzadeh, G., and G. Dhillon. 2002. "Measuring Factors that Influence the Success of Internet Commerce." Information Systems Research 13: 187-204.

[42] Tu, T. T., H. H. Chang, and Y. H. Chiu. 2011. "Investigation of The Factors Influencing The Acceptance of Electronic Cash Stored-Value Cards." African Journal of Business Management 5(1): 108-120.

[43] Yu, V. F., and H. I. Ting. 2011. "Identifying Key Factors Affecting Consumers' Choice of Wealth Management Services: An AHP Approach." The Service Industrial Journal 31(6): 929-939.

[44] Zeithaml, V. A. 1988. "Consumer Perceptions of Price, Quality, and Value: A Means-End Model and Synthesis of Evidence." Journal of Marketing, 52: 2-22. 